\title{
Adenomyosis at Hysterectomy: Prevalence, Patient Characteristics, Clinical Profile and Histopatholgical Findings
}

\author{
Shrestha $A,{ }^{1}$ Shrestha $R,{ }^{2}$ Sedhai LB, ${ }^{1}$ Pandit $U^{1}$
}

\author{
${ }^{1}$ Department of Obstetrics and Gynecology \\ ${ }^{2}$ Department of Pathology \\ Chitwan Medical College Teaching Hospital \\ Bharatpur, Nepal.
}

\section{Corresponding Author}

Anju Shrestha

Department of Obstetrics and Gynecology

Chitwan Medical College Teaching Hospital

Bharatpur, Nepal.

E-Mail: anjushr2002@yahoo.com

\section{Citation}

Shrestha A, Shrestha R, Sedhai LB, Pandit U. Adenomyosis at hysterectomy: prevalance, patient characteristics, clinical profile and histopathological findings. Kathmandu Univ Med J 2012;37(1):53-6.

\begin{abstract}
Background

Underlying adenomyosis is often the cause of treatment failure for patients undergoing medical therapy for abnormal uterine bleeding and or chronic pelvic pain. Given the limitation of ultrasonography in diagnosing adenomyosis and MRI being unaffordable to most of the patients belonging to developing countries like us, it often remains undiagnosed before a hysterectomy.
\end{abstract}

\section{Objective}

To find out the clinical profile associated with adenomyosis and to determine the prevalence of adenomyosis in hysterectomy specimens; frequency distribution, as well as to correlate clinical examination with histopathological examination.

\section{Methods}

A total of 60 women who had undergone hysterectomy with histopathologically proven adenomyosis between April 2009 and March 2010 were included . Data were collected on indication for the intervention, age, symptoms, clinical findings, hemoglobin, menopausal status, gross and histopathological findings.

\section{Results}

A total of 256 women were scheduled for hysterectomy. Adenomyosis was diagnosed in 60 of 256 cases (23.4\%). Menorrhagia (91.2\%), dysmenorrhoea $(84.2 \%)$, lower abdominal pain $(84.2 \%)$ beginning later in reproductive life (mean age- $45 \mathrm{yrs}$ ) is the classic presentation. Adenomyosis was present in 10 of 61 patients (16.3\%) with fibroids; 27 of $60(45 \%)$ with abnormal uterine bleeding; 11 of 55 (20\%) with prolapse; four of $35(11.4 \%)$ with ovarian mass; five of $25(20 \%)$ with chronic pelvic pain; three of four $(75 \%)$ with endometriosis.

\section{Conclusion}

Women undergoing hysterectomy with diagnosis of adenomyosis have a distinct symptomatology. The choice of therapy in adenomyosis is hysterectomy for those women who have completed family and had failed medical therapy .

\section{KEY WORDS \\ adenomyosis, hysterectomy, prevalence}

\section{INTRODUCTION}

Adenomyosis, a common non- malignant condition of the uterus, is characterized by the presence of endometrial glands as well as stromal elements situated at least $2.5 \mathrm{~mm}$ below the endomyometrial junction. Name Adenomyosis Synonyms "endometriosis interna", "uterine endometriosis", "internal endometriosis". The minimum distance necessary for diagnosis has been debated, but ranges from $2 \mathrm{~mm}$ to more than $4 \mathrm{~mm}$, or from one to two low-power fields. ${ }^{1}$ None of these definitions has been accepted universally.
Though the general incidence of adenomyosis has not been accurately determined, in hysterectomy specimens the incidence of adenomyosis reported in the literature varies, ranging from $5 \%$ to $70 \% .^{2-7}$ Usually adenomyosis is diagnosed mainly after hysterectomy pathologically although $\mathrm{MRI}$ is becoming more common. Despite its frequency, rare epidemiological studies on adenomyosis have been done and only little epidemiological profile of women at risk is known.

Adenomyosis induces hyperplasia and hypertrophy of 
the myometrium, thus enlarging the uterus. Clinical observation suggested that it may be related to abnormal uterine bleeding and chronic pelvic pain, although adenomyosis is often asymptomatic. ${ }^{8-10}$ When present, these symptoms lead to a presumptive preoperative diagnosis of adenomyosis and are often indication of hysterectomy.

Since the uterus is a hormonally responsive organ, hormones (oral contraceptive pills, progesterone pills, gonadotrophin hormones, progesterone intrauterine device) are the main stay of medical treatment of symptoms. These drug decrease uterine symptoms of adenomyosis, but it return quickly after the medicine wears off. ${ }^{11,12}$ Hysteroscopic endometrial ablation is good for heavy bleeding per vagina rather than menstrual cramps is if main symptoms of adenomyosis. ${ }^{13}$ However, complete eradication of deep adenomyosis is problematic and is responsible for treatment failure. Uterine artery embolization has also been used to relieve symptoms for some women, although success rates vary widely. ${ }^{14}$ Thus the purpose of this study is to evaluate the clinical profile associated with adenomyosis and to determine the prevalence of adenomyosis in hysterectomy specimens; frequency distribution, as well as to correlate clinical examination with histopathological examination.

\section{METHODS}

A hospital based cross-sectional study was carried out at Chitwan medical college teaching hospital from 1st April 2009 to 31st March 2010. Women who had undergone abdominal, vaginal or laparoscopic hysterectomy with or without salpingo- oophorectomy and with histopathologically proven adenomyosis alone or with other pathological condition were included in this study. A retrospective medical record review of hospital and ambulatory records was performed. Data were collected on indication for the intervention, age at surgery, symptoms, clinical findings, pre-op hemoglobin, menopausal status as well as gross and histopathological findings. Each pathologic specimen included the uterus with cervix. Measurements of uterus including length (I), breadth (b) and thickness (t) were noted in $\mathrm{cm}$ and size of uterus was calculated in $\mathrm{cm} 3$ (volume $=\mid \times b \times t$ ) and stratified in three groups : $<150$ $\mathrm{cm}^{3}, 150-400 \mathrm{~cm}^{3}, 401-650 \mathrm{~cm}^{3}$. Other histopathological variables were also noted, such as endometrial status, and cervical findings. Adenomyosis was diagnosed when the distance between the lower border of the endometrium and the affected myometrial area was over one-half of a low power field (i.e. $2.5 \mathrm{~mm}$ ).

The data were analyzed with Epi- Info and SPSS software. Quantitative variables were summarized by means and SD variables, following non- normal distribution by median and range. Categorical variables were summarized by frequencies (\%). One way Anova test was applied to compare the mean hemoglobin level (gm \%) and mean duration of symptoms (years) with the size of uterus.
Prevalence menorrhagia, dysmenorrhoea and chronic pelvic pain in women with various ranges of size of uterus was compared using Kruskal- Wallis $\mathrm{H}$ test. In all statistical analysis, $\mathrm{p}<0.05$ was considered statistically significant.

\section{RESULTS}

A total of 256 women were scheduled for hysterectomy. Out of which 201(78.5\%) were for total abdominal hysterectomy and laparoscopic assisted vaginal hysterectomy and 55 $(21.4 \%)$ for vaginal hysterectomy. Adenomyosis was diagnosed in 60 of 256 cases (23.4\%).

Indication of hysterectomy were divided into following categories as shown in table 1 which also show frequency distribution of adenomyosis.

Table 1. Indication for hysterectomy.

\begin{tabular}{|lll|}
\hline Group & Total & $\begin{array}{l}\text { Adenomyosis } \\
\text { present }\end{array}$ \\
\hline Abnormal heavy uterine bleeding & 60 & $27(45 \%)$ \\
\hline Fibroid & 61 & $10(16.3 \%)$ \\
\hline Prolapse & 55 & $11(20 \%)$ \\
\hline Ovarian tumor & 35 & $4(11.4 \%)$ \\
\hline Chronic pelvic pain & 25 & $5(20 \%)$ \\
\hline Endometriosis & 4 & $3(75 \%)$ \\
\hline Others & 16 & 0 \\
\hline
\end{tabular}

The mean age of patients at hysterectomy was $45 \pm 8.4$ years (range: 26-76yrs), all women were multiparous, and mean duration of symptoms persists was $4 \pm 2.1$ years (range: 1-9). The mean Hemoglobin (gm \%) level at time of hysterectomy was $10.4 \pm 1.4$ (range: $6.2-15.2$ ). Sixteen (26.7\%) women gave history of medical treatment prior to surgery which was not responding. Clinical symptoms associated with adenomyosis are considered in table 2 .

Table 2. Clinical symptoms of adenomyosis.

\begin{tabular}{|lll|}
\hline Symptoms & $\mathrm{n}=60(\%)$ & $95 \% \mathrm{Cl}$ \\
\hline Heavy uterine bleeding & $55(91.7 \%)$ & $81.6-97.2$ \\
\hline Chronic pelvic pain & $51(85 \%)$ & $73.4-92.9$ \\
\hline Dysmenorrhoea & $50(83.3 \%)$ & $71.5-91.7$ \\
\hline Dyspareunia & $9(15 \%)$ & $7.1-26.6$ \\
\hline Painful bowel movement & $5(8.3 \%)$ & $2.8-18.4$ \\
\hline Pelvic pressure & $22(36.7 \%)$ & $24.6-50.1$ \\
\hline
\end{tabular}

Thirty eight (63.3\%) women gave history of regular menstrual cycle and the rest 22(36.7\%) gave irregular. Ten patients were in menopause state and nine (90\%) among them also gave past history of menorrhagea and seven (70\%) had dysmenorrhoea and chronic pelvic pain.

Per vaginal examination findings were elaborated on table 3 , where maximum (46.7\%) had bulky uterus. Women 
having more than 10 weeks size uterus was associated with fibroid.

Table 3. Clinical examination of patient of adenomyosis.

\begin{tabular}{|lll|}
\hline Size of uterus & $\mathbf{N}(\%)$ & $95 \% \mathrm{Cl}$ \\
\hline Normal & $12(20 \%)$ & $10.8-32.3$ \\
\hline Bulky & $28(46.7 \%)$ & $33.7-60$ \\
\hline 6 Weeks & $3(5 \%)$ & $1.0-13.9$ \\
\hline 8 Weeks & $10(16.7 \%)$ & $8.3-28.5$ \\
\hline 10 Weeks & $4(6.7 \%)$ & $1.8-16.2$ \\
\hline$>10$ Weeks & $3(5 \%)$ & $1.0-13.9$ \\
\hline TOTAL & $60(100 \%)$ & \\
\hline
\end{tabular}

On per vaginal examination, only in $26(52 \%)$ cases uterine tenderness was present. The median volume of uterus is $121 \mathrm{~cm}^{3}$ (range: $14 \mathrm{~cm} 3-650 \mathrm{~cm}^{3}$ ). Table 4 shows the comparison of mean hemoglobin level and mean duration of symptoms in years with the size of the uterus with adenomyosis.

Table 4. Comparison of size of uterus with $\mathrm{Hb}$ level and duration of symptoms.

\begin{tabular}{|lll|}
\hline Size of uterus $\left(\mathrm{cm}^{3}\right)$ & Mean $\mathrm{Hb}(\mathrm{gm} \%)$ & $\begin{array}{l}\text { Mean duration of } \\
\text { symptoms(years) }\end{array}$ \\
\hline$<150(\mathrm{n}=33)$ & $10.6 \pm 1.4$ & $3.8 \pm 2.2$ \\
\hline $150-400(n=21)$ & $10.18 \pm 1.27$ & $3.52 \pm 2.4$ \\
\hline $401-650(n=3)$ & $9.5 \pm 0.8$ & $5 \pm 0.0$ \\
\hline & $F=1.36$ & $\mathrm{~F}=0.552$ \\
\hline & $P=0.26$ & $\mathrm{P}=0.57$ \\
\hline
\end{tabular}

There was no significant difference between the median volume of uterus with and without dysmenorrhoea $129 \mathrm{~cm}^{3}$ (range 14-650) and $90 \mathrm{~cm}^{3}$ (range 21-319), respectively $(p=0.483)$. The median volume of uterus was not significantly differ from the presence or absence of chronic pelvic pain i.e. $121 \mathrm{~cm}^{3}$ (range 14-650) and $108 \mathrm{~cm} 3(32-205)$, respectively $(p=0.687)$. Similarly, there

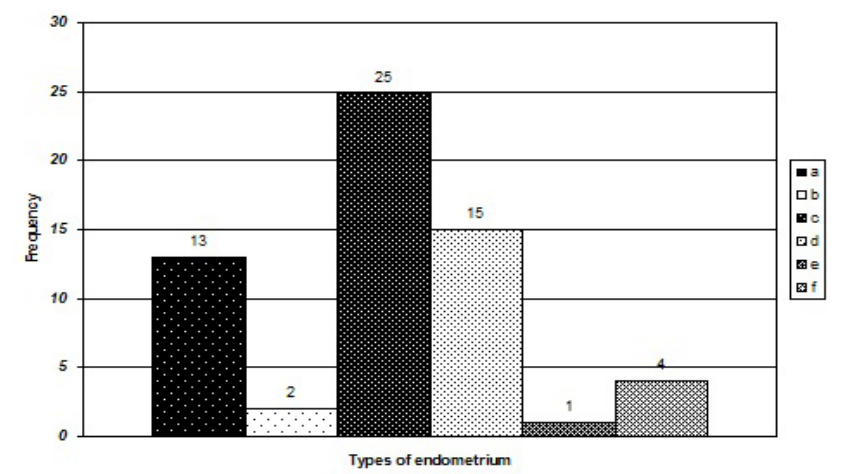

Figure 1. Types of endometrium.

a: atrophic endometrium; b: complex endometrial hyperplasia without atypia; c: proliferative endometrium; d: secretary endometrium; e: simple endometrial hyperplasia with atypia; f: simple endometrial hyperplasia without atypia. was no significant difference between the median volume of uterus with and without heavy uterine bleeding $123 \mathrm{~cm}^{3}$ (14- 650) and $90 \mathrm{~cm}^{3}(21-162)$, respectively $(p=0.4048)$. Types of endometrium in hysterectomized patient were enumerated in bar diagram, which shows that proliferative type of endometrium is maximum(41.7\%).

Histopathological examination of cervix showed: chronic cervicitis in 38 (63.3\%), chronic cervicitis with metaplasia in13 $(21.7 \%)$, carcinoma intraepithelial neoplasia in nine $(15 \%)$ cases.

\section{DISCUSSION}

As the population studied were women who had undergone hysterectomy, potential bias should be considered. Thus, these results should only refer to this group of women with adenomyosis, and cannot be generalized to all women with adenomyosis. The pathologist in this study was not aware of the study goal, and if anything, under diagnosis of the disease should tend to reduce a potential association. In this study adenomyosis was diagnosed when the distance between the lower border of the endometrium and the affected myometrial area was over one - half of a low- power field $(2.5 \mathrm{~mm})$ which was currently accepted definition. ${ }^{15}$ Our data demonstrates that adenomyosis is a common finding present in almost one- forth (23.4\%) of hysterectomy specimens of middle aged women. The reported frequency in literature is $5-70 \%{ }^{1-7}$ It was rarely diagnosed correctly preoperatively and still largely underdiagnosed as it has no special symptoms of its own. ${ }^{16}$ In our study also only in $23.3 \%$ cases adenomyosis was clinically suspected.

Menorrhagia, chronic pelvic pain and dysmenorrhoea are thought to be suggestive of and attributable to the presence of adenomyosis in clinical observation. ${ }^{8-10}$ In our study also these three symptoms were most frequently related with adenomyosis. Parazzini $F$, et al also reported that women with adenomyosis had more dysmenorrhoea and chronic pelvic pain but not dyspareunia. ${ }^{17}$ Symptoms of heavy /abnormal bleeding are thought to be positively associated with the depth of penetration of adenomyosis into myometrium. ${ }^{18,19}$ However we were not able to assess the depth of penetration, so there is the possibility that association with vaginal bleeding may be masked in our study. In the studies of chronic pelvic pain in which women had hysterectomies, the incidence of adenomyosis is 15$25 \% .^{20}$ Consistent findings have been seen in our study also i.e. $20 \%$.

Molitor JJ have suggested that the frequency of the condition increases with age until menopause and level off thereafter.21 Multiparty has been associated with an increase frequency of adenomyosis. ${ }^{1,8}$ Natural history of symptoms usually goes away after menopause. The mean age and parity in our study agrees with the literature.

Table 4 shows that bigger the size of uterus with 
adenomyosis, lesser is hemoglobin level due to heavy uterine bleeding. Similarly more the duration of symptoms persist, bigger the size of uterus is seen. But both of these values are not statistically significant.

Bergholt $T$ et al showed significant association with adenomyosis and endometrial hyperplasia. ${ }^{22}$ The results substantiate previously published findings of a relationship between high concentration of estrogen and adenomyosis and the elevated estrogen concentration in the menstrual blood of women with adenomyosis. ${ }^{23,24}$ However we could not find similar association between adenomyosis and

\section{REFERENCES}

1. Azziz R. Adenomyosis: current perspectives. Obstet Gynecol Clin N Am 1989;16:221-35.

2. Bird CC, McElin T, Manalo-Estrella P. The elusive adenomyosis of the uterus revisited. Am J Obstet Gynecol 1972;112:583-93.]

3. Lee NC, Dicker RC, Rubin GL, Ory HW. Confirmation of the preoperative diagnoses for hysterectomy. Am J Obstet Gynecol 1984;150:283-7. [Pubmed]

4. Young RH, Treger T, Scully RE. Atypical polypoid adenomyoma of the uterus: a report of 27 cases. Am J Clin Pathol 1986;139:86-90. [Pubmed]

5. Gambone JC, Reiter RC, Lench JB, Moore JG. The impact of a quality assurance process on the frequency and confirmation rate of hysterectomy. Am J Obstet Gynecol 1990;163:545-50.[Pubmed]

6. Chrysostomou M, Akalestos G, Kallistros S, et al. Incidence of adenomyosis uteri in a Greek population. Acta Obstet Gynecol Scand 1991;70:441-4.[Pubmed]

7. Vercellini P, Vigano P, Somigliana E, et al. Adenomyosis: epidemiological factors. Best Pract Res Clin Obstet Gynaecol 2006;20:465-77.

8. Merrill JA, Creasman WT. Disorders of the uterine corpus. In: Scott JR, Di Sala PJ, Hammond CB, et al., editors. Danforth's obstetrics and gynecology. 6th ed. Philadelphia: Lippincott; 1990. p. 1023.

9. Owolabi TO, Strickler RC. Adenomyosis: a neglected diagnosis. Obstet Gynecol 1977;50:424-7. [Pubmed]

10. Vercellini P, Ragni G, Trespidi L, et al. Adenomyosis: a deja vu? Obstet Gynecol Surv .1993;48:789-94. [Pubmed]

11. Ozaki T, Takahashi K, Okada M, Kurioka H, Miyazaki K. Live birth after conservative surgery for severe adenomyosis following magnetic resonance imaging and gonadotropin-releasing hormone agonist therapy. Int J Fertil Womens Med 1999 Sep-Oct;44(5):260-4. [Pubmed]

12. Fedele L, Bianchi S, Raffaelli R, Portuese A, Dorta M .Treatment of adenomyosis-associated menorrhagia with a levonorgestrel-releasing intrauterine device. Fertil Steril. 1997 Sep; 68(3):426-9. [Pubmed]

13. Quemere MP, Cravello L, Roger V, d'Ercole C, Blanc B. Impact of adenomyosis on results of endometrial ablations. Contracept Fertil Sex. 1999 May;27(5):357-63 endometrial hyperplasia. We found more of proliferative type of endometrium in hysterectomy specimen with adenomyosis.

\section{CONCLUSION}

This study shows that adenomyosis is common in women who undergone hysterectomy and that it is more frequent among women reporting dysmenorrhoea, menorrhagia and chronic pelvic pain. It is also common in those with bulky uterus. The choice of therapy of adenomyosis is hysterectomy in women with completed family and had failed medical therapy.

14. Lohle PN, De Vries J, Klazen CA, Boekkooi PF, Vervest HA, Smeets AJ,et al. Uterine artery embolization for symptomatic adenomyosis with or without uterine leiomyomas with the use of calibrated tris-acryl gelatin microspheres: midterm clinical and MR imaging follow-up. J Vasc Interv Radiol 2007 Jul;18(7):835-41.

15. Zaloudek C, Norris HJ. Mesenchymal tumours of the uterus. In: Kurman, RJ. (ed.). Blaunstein's Pathology of the Female Genital Tract. 3rd ed. New York :Springer Verlag; 1987. p. 374.

16. Weiss G, Maseelall P, Schott LL, Brockwell SE, Schocken M, Johnston JM. Adenomyosis a variant, not a disease? Evidence from hysterectomized menopausal women in the Study of Women's Health Across the Nation (SWAN). Fertil Steril 2009 Jan; 91(1):201-6.

17. Parazzini F, mais VParazzini F, Mais V, Cipriani S, Busacca M, Venturini P. Determinants of adenomyosis in women who underwent hysterectomy for benign gynecological conditions: results from a prospective multicentric study in Italy. Eur J Obstet Gynecol Reprod Bjol 2009 Aug;143(2):103-6.[Pubmed]

18. Benson RC, Sneeden VD. Adenomyosis: a reappraisal of symptomatology. Am J Obstet Gynecol .1958;76:1044-57. [PubMed]

19. Levgur M, Abadi MA, Tucker A. Adenomyosis: symptoms, histology, and pregnancy terminations. Obstet Gynecol 2000 May;95(5):688-91. [Pubmed]

20. Vercellini P, Parazzini F, Oldani S, Panazza S, Bramante T, Crosignani PG. Adenomyosis at hysterectomy: a study on frequency distribution and patient characteristics. Hum Reprod 1995;10:1160-2. [PubMed]

21. Molitor JJ. Adenomyosis: A clinical and pathologic appraisal. Am J Obstet Gynecol 1971;110:275- 84.

22. Bergholt T, Eriksen L, Berendt N, Jacobsen M, Hertz JB. Prevalence and risk factors of adenomyosis at hysterectomy. Hum Reprod 2001;16:2418-21.

23. Parazzini F, Vercellini P, Panazza S, Chatenoud L, Oldani S, Crosignani PG. Risk factors for adenomyosis. Hum Reprod 1997;12:1275-9.

24. Takahashi K, Nagata $\mathrm{H}$ and Kitao M. Clinical usefulness of determination of estradiol level in the menstrual blood for patients with endometriosis. Acta Obstet Gynaecol Jpn 1989;41: 1849-50. 